\title{
Student Characteristics and Enrollment in a CTE Pathway Predict Transfer Readiness
}

\author{
Renah Wolzinger ${ }^{1 *}$, Henry O'Lawrence ${ }^{2}$ \\ ${ }^{1}$ CSULB, 1250 Bellflower Blvd., CA, 90840 Long Beach, UNITED STATES \\ 2 Saddleback College, CA, UNITED STATES
}

*Corresponding Author: rwolzinger@saddleback.edu

Citation: Wolzinger, R. and O'Lawrence, H. (2018). Student Characteristics and Enrollment in a CTE Pathway Predict Transfer Readiness. Pedagogical Research, 3(2), 08. https://doi.org/10.20897/pr/91653

Published: June 14, 2018

\begin{abstract}
This research predicts transfer readiness of student's characteristics and enrollment in CTE pathway; and most significantly addressed statewide CTE transfer students that meet the transfer requirements under CTE Taxonomy of program (TOP) code for students who transfer to a California State University (CSU), and Private or out-of-state university. There is a lack of adequate pathways for CTE students to prepare for transfer to the California State University system. The CTE pathways include a high number of underrepresented students, compounding the problem of equity in current transfer policy. Research indicates that students in career and technical education pathways have a limited path toward a university transfer. Policy has been enacted to improve transfer processes between California community colleges and the CSU system, however the policy does not directly address barriers for students in CTE programs.
\end{abstract}

Keywords: scheduling, private schools, public schools, athletics, open spaces

\section{INTRODUCTION}

To address the transfer problem, in 2010 the California legislature enacted Senate Bill 1440 (Padilla). SB1440 requires the community colleges and the CSU to work together to develop Associate Degrees for Transfer (ADT). Students completing the ADT with a minimum 2.0 GPA would receive registration priority at a CSU in their area and in a major similar to their community college major, if it is available. They will enter with junior standing and will complete 60 additional units to graduate with a bachelor's degree. This law was aimed at reducing the number for courses and units needed to transfer, and reducing the overall time it takes to complete a bachelor's degree. The law does not explain how this might be achieved, as it is left for key leadership in higher education to develop a successful plan (Patton, 2012).

Faculty at the California community college and the CSU system have worked together to design the associate degrees for transfer in over 30 majors, but have not incorporated many majors associated with Career and Technical Education (CTE) courses (Patton, 2012). CTE refers to courses designated in the course outline of record as occupational. These courses typically include applied learning simulating problem solving incorporating equipment used in the workplace. CTE was formerly coined vocational education, and was an integral part of the community college mission since its inception (Koos, 1921).

Students interested in a CTE area who wish to transfer may have to find an alternative pathway or complete a transfer major outside of their area of interest. This problem may create extra time for students to pursue a transfer degree, and may uncover an equity gap for underserved populations of students in CTE who are not able to complete a pathway to a four-year institution. 
The design of a transfer degree between a community college and a four-year institution has several important components. Kisker (2012) describes the elements of effective transfer degrees related to student persistence as including common general education requirements, early pre-major pathways, transfer of credits, transfer as junior status, priority admission, four-year degree credit limits, and acceptance into upper division courses. Each of these elements contribute to increased transfer and degree completion when included in the design of a transfer curriculum. Common general education requirements accepted as a block to a receiving public university regardless of their own general education patterns simplifies lower division scheduling and eliminates many roadblocks. Common pathways have been implemented in CA for many transfer majors, mostly non-technical. Transfer of credits has been a barrier for many technical programs, as course design differs between community college and universities. These elements emphasize the need to develop better pathways for students in career and technical education. Each of these factors affect the ability to transfer as junior standing to a university (Kisker, 2012).

\section{Research Purpose}

The purpose of this research was to determine if student's characteristics and enrollment in CTE pathway predict transfer readiness. In California, the statewide data provides an analysis of the state transfer for CTE students, however it does not provide findings to particular single institution. Therefore, this research addressed statewide CTE transfer students that meet the transfer requirements under a CTE Taxonomy of Program (TOP) code for students who transfer to a CSU, private or out-of-state university. For point of clarification, transfer students from CTE areas as designated by the California Chancellor's TOP code system are included in the analysis using Taxonomy of Program (TOP) code to distinguish students in CTE pathways. The technical requirements for jobs require more skills and the research has shown advantages to those who transfer and complete a bachelor degree to be competitive in the job market. This study linked CTE pathways with enrollments and transfer data to understand which types of students are enrolling in CTE pathways and if they are becoming transfer ready.

\section{Problem Statement and Conceptual Framework}

Pathways in CTE areas that lead to transfer to a CSU are far less prevalent than transfer pathways in other academic areas (Moore, 2014). CTE pathways have many definitions, however for this study CTE pathways refers to the courses identified by the same two-digit Taxonomy of program (TOP) code. The TOP code is a numerical designation of a type of program offered. TOP code is used at the state level to gain information on programs that have similar outcomes. There is an increase in the number of projected job openings in the next decade requiring a four-year degree and technical skills, informing us that new practices are needed to grow the pathways for CTE and transfer (Carnavale, 2013). Carnavale found that $24 \%$ of all jobs require a bachelor degree and are concentrated in managerial, office and education clusters (Carnavale, 2012). As educators prepare the future workforce in California, they need to design and implement clear transfer pathways for students (Moore, 2014). The CTE/Transfer pathway addresses both providing pathways for learning technical skills leading to a four-year degree, and training our diverse population in California to prepare for middle skill jobs, such as those found in office and administrative services, construction, healthcare, and protective services.

\section{REASEARCH METHODS}

This quantitative study examined the pathways for CTE students that lead to an Associate's Degree for Transfer (ADT) to a California State University. The current development of ADTs in CTE areas and student outcomes was examined. The equity gap between CTE student transfers and academic transfers was also explored. Data is also available statewide by college and TOP code on CTE student outcomes, including student characteristics. Utilizing the inferential statistics in a large data set enables the researcher to make generalizations about the greater population (Morgan, 2012). The statewide study provides new information about CTE pathways and transfer when looking at the two data sets.

\section{Instrumentation}

The California Community Colleges Chancellor's Office Management Information Systems Data Mart is a statewide data system that includes student data submitted by the 113 California Community Colleges (http://datamart.cccco.edu/datamart.aspx). The Data Mart provides information about students, courses, student services, and student outcomes. This database is available for public query to provide information sought by researchers, practitioners or others to answer questions related to the California community colleges. Cal-PASS Plus is a database that contains annual student level data from the California Department of Education K-12 CalPads data, California Community College MIS data, and many CSU and UC institutions (https://www.calpassplus.org). The survey data from the California Employment Outcome Survey is also included in the Cal-PASS Plus database. This database is used to answer questions about California community college 
student outcomes, including the pathways and outcomes students experience moving from one system to another and post college experiences (Table 1). Data Tools used in the Study to evaluate CTE Transfer Programs presents a summary of these data tools and the study purpose of each tool.

Research question one addresses how student characteristics and enrollment in a CTE pathway predict transfer readiness. To answer this question, a logistic regression was used. A logistic regression test was used "to predict a categorical variable from a set of predictor variables" (Leech, 2015, p. 167). A logistic regression test is used to predict a dichotomous outcome (Morgan, 2012). Logistic regression was conducted to assess whether eighteen predictor variables (age, foster youth, financial aid, skills builder, female, other gender, African American, Asian, Filipino, Pacific Islander, Other Ethnicity, Architecture, Business Management, Media and Communications, Information Technology, Education, Engineering and Industrial Technology, and Commercial Services) significantly predict whether a student became transfer ready. The model was checked for the assumptions that variables were linearly related and the conditions were checked and met.

Research question two addresses how enrollment in a CTE pathway predicts time to transfer readiness. To answer this question, a multiple regression was used. The dependent variable is time to transfer readiness. The independent variables are age, gender, ethnicity, students with disabilities, first generation students, students who received financial aid, basic skills students, and the top fifteen CTE pathways.

\section{FINDINGS}

The first research question in the study addressed how student characteristics and enrollment in a CTE pathway predict transfer readiness. When all eighteen variables were considered together, they significantly predicted whether a student becomes transfer ready $\left(\chi^{2}=7136.34, d f=32 . N=65,535 p<.001\right)$. The log likelihood in Block 1 was 46070.251, and in Block 2 it was 45395.134, indicating that the second model is a better fitting model. The analysis below begins with Model 2, which included student characteristics with the addition of CTE pathways designated by Taxonomy of Program code.

The classification Table 1 below shows that overall there is a predictive capacity of $86 \%$. This refers to the participants that were predicted correctly as becoming transfer ready using the significant variables in the model, the same number as found in Model 1. The table also shows a prediction of 8374 students becoming transfer ready, and 56,050 students not becoming transfer ready. Therefore, adding variables between Model 1 and Model 2 did not change the predictability of participants becoming transfer ready. The tables in the equation for Block 1 shows that there is not an equal number of transfer ready and non-transfer ready students. There is an $84 \%$ greater likelihood of a student not becoming transfer ready $\operatorname{Exp}(B)=.160$. The omnibus model shows that when we consider all eighteen predictors together, the model equation is significant $\left(\chi^{2}=675.111, d f=16 . N=65,535, p<\right.$ $.001)$.

Table 1. Predictive Model of Students Becoming Transfer Ready

\begin{tabular}{llccc}
\hline \multicolumn{5}{c}{ Step 1 } \\
Observed & & $\begin{array}{c}\text { Predicted Transfer Ready } \\
\text { (Yes) }\end{array}$ & $\begin{array}{c}\text { Predicted Transfer Ready } \\
\text { (No) }\end{array}$ & Percentage Correct \\
\hline Not Transfer Ready & no & 56050 & 460 & 99.2 \\
\hline Transfer Ready & yes & 8374 & 651 & 86.5 \\
\hline
\end{tabular}

Note. The cut value is .500

Table 2 below presents the odds ratios, which suggest that the odds of becoming transfer ready increase the most if a student is enrolled in architecture, business management, or information technology. The odds of becoming transfer ready also increase if the student is Asian, receiving financial aid, or is a skills builder (taking at least 5 units in the same two-digit top code). The odds of not reaching transfer ready status are significant for older students, foster youth, other gender, African American, Filipino, Pacific Islander, other ethnicity. The odds of not reaching transfer readiness are also significant for students enrolled in engineering and industrial technology and commercial services.

Table 2. Variance on Whether Students Became Transfer Ready

\begin{tabular}{lrrr}
\hline Step & $\mathbf{- 2 ~ L o g ~ l i k e l i h o o d ~}$ & Cox \& Snell R Square & Nagelkerke R Square \\
\hline 1 & $45395.134^{a}$ & .103 & .187 \\
\hline${ }^{a}$ Note. Estimation terminated at iteration number 20 because maximum iterations have been reached. &
\end{tabular}

The odds of becoming transfer ready are denoted by $\operatorname{Exp}(\mathrm{B})$, and are highest for students who are in the pathways for Architecture, Business Management or Information Technology. The student characteristics 
contributing the highest amount to becoming transfer ready include students who received financial aid, students who were skills builders (returned to college to take additional courses related to a job), or were Asian. The characteristics that predict that a student is less likely to persist in becoming transfer ready are older students, foster youth, students who identify as other gender, African American, Filipino, Pacific Islander, or other ethnicity. There is also a negative effect for prediction to becoming transfer ready in Engineering and Industry Technology and Commercial Services pathways. The negative effect indicates there is a prediction that these groups take longer to become transfer ready.

In the logistic regression model, whether a student became transfer ready during the five-year study period between Fall 2009 through Spring 2015 (transfer ready) was the dependent variable, and student characteristics and CTE pathway (two-digit top code) were the independent variables. The variables not in the equation table show that ten of the sixteen variables (age, financial aid, first generation, skills builders, other genders, African American, Asian, Filipino, two or more races, and Other Ethnicity) within the set of variable proposed were found to be significant. These variables are individually significant predictors as to whether students became transfer ready. This indicates that the subsequent models should yield significant results about predictors to transfer readiness. The omnibus model shows that when we consider all ten predictors together, the model equation is significant $\left(\chi^{2}=6461.23, d f=16 . N=65,535, p<.001\right)$.

In block one of the linear regression model, there were eleven significant variables that predict a student becoming transfer ready, including age, financial aid, disabled, skills builder, female, other gender, African American, Asian, Filipino, Pacific Islander, or other ethnicity. The odds of becoming transfer ready are denoted by $\operatorname{Exp}(B)$, and are highest for students who are skills builders or who are Asian. Skills Builders in this model are students who took five units or more in the same pathway as denoted by two-digit top code. There were twelve statistically significant variables found to predict length of time to transfer, $F(28,8996)=45.73, p<.001$. These variables included age, ethnicity if identified as Asian, Filipino or two or more races, received financial aid, was disabled, first-generation college students, or took basic skills courses. Pathways that predicted transfer readiness $F(15,9009)=82.70, p<.001$ were Education, Health, Family and Consumer Science and Law. Significant regression coefficients for all variable are represented in Table 3 below.

Table 3. Predictors to Becoming Transfer Ready

\begin{tabular}{|c|c|c|c|c|c|c|}
\hline \multicolumn{7}{|c|}{ Step 1} \\
\hline & $\mathrm{B}$ & S.E. & Wald & df & Sig. & $\operatorname{Exp}(B)$ \\
\hline Age & -.156 & .004 & 1491.638 & 1 & .000 & .855 \\
\hline Foster & -.365 & .207 & 3.107 & 1 & .078 & .695 \\
\hline Fin Aid & .484 & .026 & 344.385 & 1 & .000 & 1.622 \\
\hline$\overline{\text { Disabled }}$ & -.141 & .064 & 4.803 & 1 & .028 & .869 \\
\hline First Gen & -.028 & .060 & .222 & 1 & .638 & .972 \\
\hline Skills Builder & .920 & .025 & 1391.015 & 1 & .000 & 2.508 \\
\hline Basic Skills & .005 & .025 & .041 & 1 & .840 & 1.005 \\
\hline Female & .052 & .024 & 4.742 & 1 & .029 & 1.054 \\
\hline Other Gender & -.721 & .185 & 15.232 & 1 & .000 & .486 \\
\hline African Am & -1.114 & .068 & 265.937 & 1 & .000 & .328 \\
\hline Amer. Indian & -.268 & .175 & 2.339 & 1 & .126 & .765 \\
\hline Asian & .720 & .036 & 390.808 & 1 & .000 & 2.054 \\
\hline Filipino & -.409 & .032 & 165.767 & 1 & .000 & .665 \\
\hline Two or More Races & .065 & .071 & .831 & 1 & .362 & 1.067 \\
\hline Pacific Islander & -.394 & .175 & 5.052 & 1 & .025 & .674 \\
\hline Other & -.124 & .038 & 10.755 & 1 & .001 & .883 \\
\hline Constant & .813 & .084 & 94.018 & 1 & .000 & 2.255 \\
\hline
\end{tabular}

The second research question addressed how long it took students to become transfer ready. To investigate how student characteristics and enrollment in a CTE pathway predict time to transfer readiness, a multiple regression was conducted using the number of years it took to become transfer ready (Transfer Year) as the dependent variable, and students' characteristics and a set of dummy variables for each of the transfer pathways, with students not in a CTE pathway as the omitted reference group. Top codes that had less than 50 students that were transfer ready within the five-year study period were eliminated from the analysis. These excluded top codes include Environmental Science (Code 03), Biological Science (Code 04), Humanities (Code 15), Physical Sciences (Code 19), Social Sciences (Code 22), and Interdisciplinary Studies (Code 49). These areas of study typically do not include courses designated as CTE, and therefore have a very low number of CTE enrollments in the database.

There were twelve statistically significant variables found to predict length of time to transfer, $F(28,8996)=$ $45.73, p<.001$. These variables included age, ethnicity if identified as Asian, Filipino or two or more races, received financial aid, was disabled, first-generation college students, or took basic skills courses. Pathways that predicted 
transfer readiness $F(15,9009)=82.70, p<.001$ were Education, Health, Family and Consumer Science and Law. Significant regression coefficients for all variable are represented in Table 4 below.

Table 4. Predictors to Becoming Transfer Ready

\begin{tabular}{lcccccr}
\hline & \multicolumn{1}{c}{ Step 1 } & & \\
\hline & B & S.E. & Wald & df & Sig. & Exp(B) \\
\hline Age & -.156 & .004 & 1491.638 & 1 & .000 & .855 \\
\hline Foster & -.365 & .207 & 3.107 & 1 & .078 & .695 \\
\hline Fin Aid & .484 & .026 & 344.385 & 1 & .000 & 1.622 \\
\hline Disabled & -.141 & .064 & 4.803 & 1 & .028 & .869 \\
\hline First Gen & -.028 & .060 & .222 & 1 & .638 & .972 \\
\hline Skills Builder & .920 & .025 & 1391.015 & 1 & .000 & 2.508 \\
\hline Basic Skills & .005 & .025 & .041 & 1 & .840 & 1.005 \\
\hline Female & .052 & .024 & 4.742 & 1 & .029 & 1.054 \\
\hline Other Gender & -.721 & .185 & 15.232 & 1 & .000 & .486 \\
\hline African Am & -1.114 & .068 & 265.937 & 1 & .000 & .328 \\
\hline Amer. Indian & -.268 & .175 & 2.339 & 1 & .126 & .765 \\
\hline Asian & .720 & .036 & 390.808 & 1 & .000 & 2.054 \\
\hline Filipino & -.409 & .032 & 165.767 & 1 & .000 & .665 \\
\hline Two or More Races & .065 & .071 & .831 & 1 & .362 & 1.067 \\
\hline Pacific Islander & -.394 & .175 & 5.052 & 1 & .025 & .674 \\
\hline Other & -.124 & .038 & 10.755 & 1 & .001 & .883 \\
\hline Constant & .813 & .084 & 94.018 & 1 & .000 & 2.255 \\
\hline
\end{tabular}

Students who were Asian or were identified as two or more races became transfer ready faster than other students did. The remaining significant indicators to that showed students becoming transfer ready as a slower rate included age, ethnicity of Filipino, received financial aid, identified as disabled, first generation college student, took basic skills courses, or were enrolled in the pathways for education, health, family and consumer sciences or law. The most significant factor relating to a student becoming transfer ready was whether a student took basic skills courses, with a beta of $0.185, \mathrm{p}<.001$, indicating the students in this category took longer to become transfer ready. The adjusted $R^{2}$ in Model 1 was .120, and the adjusted $R^{2}$ in model 2 was .122. This indicated that the model explained $12 \%$ of the variance in transfer ready status, and that $.002 \%$ of the variance is explained by the addition of pathways to the model.

Table 5. Significant Predictors to a How Many Years It Takes to Become Transfer Ready

\begin{tabular}{|c|c|c|c|}
\hline Variable & $B$ & $p$ & $t$ \\
\hline Age & 0.052 & $* * *$ & 5.138 \\
\hline Asian & -0.106 & $* * *$ & -9.200 \\
\hline Filipino & 0.087 & $* * *$ & 7.222 \\
\hline Two or More Races & -0.026 & $*$ & -2.523 \\
\hline Financial Aid & 0.149 & $* * *$ & 14.621 \\
\hline Disabled & 0.042 & $* * *$ & 4.251 \\
\hline First Generation & 0.040 & $* * *$ & 3.989 \\
\hline Basic Skills & 0.185 & $* * *$ & 18.273 \\
\hline$\overline{R^{2}}$ & 0.120 & & \\
\hline$F(15,9009)$ & 82.70 & $* * *$ & \\
\hline TOP 08 Education & 0.037 & $*$ & 2.263 \\
\hline TOP 12 Health & 0.071 & $*$ & 2.344 \\
\hline TOP 13 Family and Cons. Sci. & 0.077 & $*$ & 2.237 \\
\hline TOP 14 Law & 0.036 & $* *$ & 2.614 \\
\hline$\overline{\mathrm{R}^{2}}$ & 0.122 & & \\
\hline$\overline{\Delta R^{2}}$ & 0.002 & & \\
\hline$F(28,8996)$ & 45.73 & $* * *$ & \\
\hline
\end{tabular}

To look at the number of students becoming transfer ready by CTE pathway and year, the following table was constructed. This shows the quickest CTE pathways for students becoming transfer ready were Business Management, Information Technology, Public and Protective Services, Family and Consumer Science, and Health (see Table 5). The CTE pathways that showed the least likelihood of becoming transfer ready were Interdisciplinary Studies, Commercial Services, Law, Education, Agriculture and Architecture. It should be noted that Law refers to only the CTE designated courses in the Law pathway. To look at the number of students 
becoming transfer ready by CTE pathway and year, Table 6 was constructed. This shows the quickest CTE pathways for students becoming transfer ready were Business Management, Information Technology, Public and Protective Services, Family and Consumer Science, and Health (see Table 6). The CTE pathways that showed the least likelihood of becoming transfer ready were Interdisciplinary Studies, Commercial Services, Law, Education, Agriculture and Architecture. It should be noted that Law refers to only the CTE designated courses in the Law pathway.

Table 6. Number of Years to Become Transfer Ready by Top Code

\begin{tabular}{|c|c|c|c|c|c|c|c|c|c|}
\hline \multirow[b]{2}{*}{ Pathway } & \multicolumn{9}{|c|}{ Time to Transfer Readiness } \\
\hline & $\begin{array}{l}\text { Top } \\
\text { Code }\end{array}$ & $\begin{array}{c}2 \\
\text { Years }\end{array}$ & $\begin{array}{c}3 \\
\text { Years }\end{array}$ & $\begin{array}{c}4 \\
\text { Years }\end{array}$ & $\begin{array}{c}5 \\
\text { Years }\end{array}$ & $\begin{array}{c}6 \\
\text { Years }\end{array}$ & $\begin{array}{c}\text { Total Trans. } \\
\text { Ready }\end{array}$ & $\begin{array}{c}\text { Total } \\
\text { Students in } \\
\text { the Pathway }\end{array}$ & $\begin{array}{c}\text { Percent } \\
\text { Trans. } \\
\text { Ready }\end{array}$ \\
\hline Agriculture & 01 & 7 & 27 & 21 & 14 & 6 & 75 & 433 & $17.32 \%$ \\
\hline Architecture & 02 & 7 & 28 & 2 & 16 & 7 & 60 & 204 & $29.41 \%$ \\
\hline Business Management & 05 & 230 & 543 & 370 & 237 & 129 & 1509 & 4625 & $32.63 \%$ \\
\hline Media and Comm. & 06 & 21 & 72 & 54 & 35 & 23 & 205 & 888 & $23.09 \%$ \\
\hline Information Tech & 07 & 76 & 172 & 123 & 84 & 49 & 504 & 1590 & $31.70 \%$ \\
\hline Education & 08 & 6 & 17 & 17 & 14 & 11 & 65 & 233 & $27.90 \%$ \\
\hline Eng. \& Ind. Tech & 09 & 23 & 73 & 48 & 37 & 26 & 207 & 2142 & $9.66 \%$ \\
\hline Fine \& Applied Arts & 10 & 15 & 56 & 41 & 31 & 10 & 153 & 739 & $20.70 \%$ \\
\hline Health & 12 & 30 & 100 & 83 & 74 & 47 & 334 & 1768 & $18.89 \%$ \\
\hline Family \& Cons Science & 13 & 31 & 146 & 120 & 83 & 64 & 444 & 2521 & $17.61 \%$ \\
\hline Law & 14 & 6 & 8 & 4 & 11 & 9 & 38 & 211 & $18.01 \%$ \\
\hline Pub \& Prot. Services & 21 & 33 & 136 & 122 & 96 & 58 & 445 & 2713 & $16.40 \%$ \\
\hline Commercial Services & 30 & 2 & 7 & 9 & 4 & 1 & 23 & 253 & $9.09 \%$ \\
\hline Interdisciplinary Stud. & 49 & 5 & 5 & 49 & 2 & 0 & 61 & 141 & $43.26 \%$ \\
\hline Total & & 492 & 1390 & 1063 & 738 & 440 & 4123 & 18161 & \\
\hline
\end{tabular}

Note: (eliminated top codes $<50$, environmental science, biological science, foreign language, humanities, library science, math, physical science, social science)

\section{SUMMARY AND CONCLUSION}

The analysis reported here showed that there several significant pathways and student characteristics that predict transfer readiness and time to transfer readiness. The chi-squared analysis showed that underrepresented students are enrolling at a higher rate than expected in CTE pathways that have a low number of students reaching transfer readiness. The analysis also showed that CTE students from underrepresented populations are taking longer to reach transfer readiness those other students.

There was heavy enrollment for CTE students in Business and Management (4625 students) compared to other pathways. This was followed by Public and protective Services (2713 students), Family and Consumer Sciences (2521 students), Engineering and Industrial Technologies (2142 students), Health (1768 students) and Information Technology (1590 students). These top enrolled pathways account for $82 \%$ of the CTE students found in the dataset. The remaining pathways in the top 15 were Media and Communications (888 students), Fine and Applied Arts (739 students), Agriculture and Natural Resources (422 students), Commercial Services (253 students), Education (233 students), Law (221 students), Architecture and Environmental Design (204 students), Interdisciplinary Studies (141 students), and Biological Sciences (47 students). These findings show how that most CTE students are enrolled in Business and Management, and the top six pathways by enrollment include most CTE students. This finding is interesting as many California community colleges have large portfolios of CTE programs including many certificate offerings. The literature review included that both students and employers are confused on these various offerings and that they diminish the value of many CTE programs.

The student characteristics that were significant predictors to reaching transfer ready status were Asian, receiving financial aid, or skills builders (students who took five or more units in the same TOP code). CTE pathways that lead to transfer ready status were architecture, business management, or information technology. These successful pathways in terms of transfer readiness encompass 34\% of CTE students in the study. It is consistent in the literature that Asian students are found to be achieving transfer readiness at a higher rate than other students (Budd and Stowers, 2014). Students receiving financial aid would lose their financial aid eligibility upon dropping below the required unit threshold, and are consistent with completing a program. Skills builders are those students who take at least five units in the same top code, and are found to be continuing in their area of concentration to transfer readiness. The strong pathways found here that lead to transfer readiness: architecture, business management, or information technology, are all fields that have well-developed transfer pathways to the CSU system leading to a Bachelor's degree. 
The student characteristics found not to be transfer readiness were older students, foster youth, other gender, African American, Filipino, Pacific Islander, other ethnicity. The pathways found where students did not reach transfer readiness were engineering and industrial technology and commercial services. The pathways that were found to significantly predict a longer time to become transfer ready in the multiple regression analysis were Education, Health, Family and Consumer Science and Law. Family and Consumer Science include programs in Child Development, Nutrition Foods and Culinary Arts, and Hospitality. All of these program that take longer to reach a transfer ready status involve some kind of license requirement in order to work in the field. The requirement may be related to students' persistence in completing the lower division program and/or completing the requirements for transfer even if it takes extra years to complete the courses. No pathways were found that significantly predicted a shorter time to transfer in this study.

Looking at how many years it took students to become transfer ready by CTE pathway, only Business Management (230 students) and Information and Communication Technologies (76) students had over 50 students that became transfer ready within two years. The multiple linear regression used to identify which pathways predict time to degree found that found that the significant pathways were Education, Health, Family and Consumer Science and Law. Although these were significant, predictors for how many years it takes to become transfer ready, only pathways explained two $\%$ of the model. The most significant effect on the number of years to become transfer ready was whether a student took basic skills courses (with a beta of $0.185, p<.001$ ). This indicates that students who took basic skills courses took longer to transfer than other students. The regression analysis indicated that SB 1440 (The Student Transfer Achievement Reform Act) as designed is not having the desired impact for most CTE pathways.

This legislation stipulates that a student may transfer to a CSU if they meet a set of criteria including completion of an associate degree for transfer offered at a maximum of 60 units and obtain a minimum 2.0 GPA. Several pathways had more than 50 students becoming transfer ready after three years including Business Management (543), Information Technology (172), Engineering and Industrial Technology (73), Fine and Applied Arts (56), Health (100), Family and Consumer Science (146), and Public and Protective Services (122). The highest number of students becoming transfer ready occurred in year three (1390) of the study when totaling all students who became transfer ready. Year 4 was the next highest year of students becoming transfer ready (1063); with a drop off in students becoming transfer ready in five years or six years.

The number of years it took CTE students to transfer could be related to students taking career programs over a two-year period, and then completing GE requirements. CTE programs include lab time and are difficult to schedule at the same time as completing other courses. In addition, CTE courses are many times taught when faculty are available to teach, and not necessarily during the best time for students who are taking GE courses to transfer. For this study, strong pathways were defined as more students becoming transfer ready. The analysis yielded twelve significant pathways in the model when looking at how underrepresented students enrolled in CTE pathways. Underrepresented students included Hispanic, African American, Pacific Islander, or Native American/Alaska Native.

\section{REFERENCES}

Budd, D. and Stowers, G. N. (2014). Group differences in California community college transfers. Community College Journal of Research and Practice, (ahead-of-print), 1-15.

California 2015-2016 State Budget. (2015). Available at: http:/ /www.dof.ca.gov/documents/FullBudgetSummary2015.pdf

California Community Colleges Chancellor's Office. (2014). California community colleges sets goal to increase student completions by nearly a quarter of a million statewide (Press Release August 27, 2014). Sacramento, CA: Paige Marlatt Dorr.

Available

at:

http://californiacommunitycolleges.cccco.edu/Portals/0/DocDownloads/PressReleases/AUG2014/PR_B

OG_GOALS_for_8-27-14_Press_Conf_news_release_FINAL_8-22-14.pdf

California Community College Chancellors Office. (2015a). 2014-2015 Career Technical Education CTE Enhancement Fund Report. Sacramento: California Community College Chancellors Office.

California Community Colleges Chancellor's Office. (2015b). Course identification numbering system. Available at: http:/ / c-id.net/degreereview.html

California Community Colleges Chancellor's Office. (2015c). Board of Governors Task Force on Workforce, Job Creation, and a Strong Economy. Sacramento: California Community College Chancellors Office.

California Community Colleges Chancellor's Office. (2015d). First California Community College Bachelor's Degree Programs Receive Initial Approval from Board of Governors. Sacramento: California Community College Chancellors Office. 
California Community Colleges Chancellor's Office. (2016e). Associate Degree for Transfer. Sacramento: California Community College Office. Available at: http:/ / californiacommunitycolleges.cccco.edu/Students/AssociateDegreefor'Transfer.aspx

California Community College Chancellor's Office. (2012). Focus on results: Accountability reporting for the California community colleges. Available at: http:/ / extranet.ccco.edU/Portals/1/TRIS/Research/Accountability/ARCC/ARCC\%202012\%20March\%2 OFinal.pdf

California Postsecondary Education Commission, Trend Analysis-Transfer Totals. (2011). Community college to California state university-full year transfers 1989/90 to 2009/10. Available at: http://www.cpec.ca.gov/OnLineData/Transfer'Totals.asp?Seg=B

California State Education Code. (2013). Ed Code 66745-66749. Available at: www.sb1440.org/portals/4/sb1440home/policy/edcode 66745-66749.pdf

California State Legislature. (2010). Senate bill $1440 . \quad$ Available at: http://www.sb1440.org/Portals/4/sb1440home/Policy/sb_1440_bill_20100929_chaptered.pdf

Kisker, C. B., Wagoner, R. L. and Cohen, A. M. (2012). Elements of effective transfer associate degrees. New Directions for Community Colleges, 2012(160), 5-11. https://doi.org/10.1002/cc.20033

Koos, L. V. (1921). Current Conceptions of the Special Purposes of the Junior College. The School Review, $520-529$. https://doi.org/10.1086/437428

Leech, N. L., Barrett, K. C. and Morgan, G. A. (2015). IBM SPSS for intermediate statistics: Use and interpretation. Routledge.

Moore, C. and Shulock, N. (2014). From community college to university: Expectations for California's new transfer degrees. California State University, Sacramento. Sacramento, CA: Institute for Higher Education Leadership \& Policy.

Morgan, G. A., Leech, N. L., Gloeckner, G. W. and Barrett, K. C. (2012). IBM SPSS for introductory statistics: Use and interpretation. Routledge.

Patton, J. and Pilati, M. (2012). Faculty reflections on implementing associate degrees for transfer in California. New Directions for Community Colleges, 2012(160), 55-68. https://doi.org/10.1002/ cc.20038 


\section{APPENDIX A}

\section{LOGISTIC REGRESSION TABLE}

Logistic Regression, All Variables Variables in the Equation

\begin{tabular}{|c|c|c|c|c|c|c|}
\hline \multicolumn{7}{|c|}{ Step 1a } \\
\hline & B & S.E. & Wald & df & Sig. & $\operatorname{Exp}(B)$ \\
\hline Age & -.158 & .004 & 1495.341 & 1 & .000 & .854 \\
\hline Foster & -.417 & .211 & 3.898 & 1 & .048 & .659 \\
\hline Fin Aid & .503 & .026 & 364.959 & 1 & .000 & 1.653 \\
\hline Disabled & -.104 & .065 & 2.598 & 1 & .107 & .901 \\
\hline First Gen & -.032 & .061 & .283 & 1 & .595 & .968 \\
\hline Skills Builder & .494 & .184 & 7.228 & 1 & .007 & 1.639 \\
\hline Basic Skills & .018 & .026 & .501 & 1 & .479 & 1.018 \\
\hline Female & .054 & .025 & 4.721 & 1 & .030 & 1.056 \\
\hline Other Gender & -.720 & .186 & 15.041 & 1 & .000 & .487 \\
\hline African American & -1.125 & .069 & 268.484 & 1 & .000 & .325 \\
\hline American Indian & -.260 & .176 & 2.175 & 1 & .140 & .771 \\
\hline Asian & .638 & .037 & 295.345 & 1 & .000 & 1.892 \\
\hline Filipino & -.398 & .032 & 154.211 & 1 & .000 & .672 \\
\hline Two Or More Races & .054 & .072 & .578 & 1 & .447 & 1.056 \\
\hline Pacific Islander & -.420 & .177 & 5.630 & 1 & .018 & .657 \\
\hline Other Ethnicity & -.139 & .038 & 13.238 & 1 & .000 & .870 \\
\hline TOP01 Agriculture & .126 & .226 & .309 & 1 & .578 & 1.134 \\
\hline TOP02 Architecture & 1.083 & .239 & 20.540 & 1 & .000 & 2.954 \\
\hline TOP05 Business Management & .975 & .186 & 27.401 & 1 & .000 & 2.652 \\
\hline TOP06 Media And Communications & .463 & .201 & 5.292 & 1 & .021 & 1.589 \\
\hline TOP07 Information Tech & .934 & .193 & 23.558 & 1 & .000 & 2.546 \\
\hline TOP08 Education & .658 & .239 & 7.596 & 1 & .006 & 1.930 \\
\hline TOP09 Eng. and Industrial Tech & -.464 & .198 & 5.479 & 1 & .019 & .629 \\
\hline TOP10 Fine and Applied Arts & .222 & .206 & 1.163 & 1 & .281 & 1.249 \\
\hline TOP11 Foreign Lang & -14.055 & 40192.970 & .000 & 1 & 1.000 & .000 \\
\hline TOP12 Health & .208 & .194 & 1.156 & 1 & .282 & 1.232 \\
\hline TOP13 Family and Consumer Science & .124 & 191 & .421 & 1 & .517 & 1.132 \\
\hline TOP14 Law & .372 & .266 & 1.953 & 1 & .162 & 1.451 \\
\hline TOP16 Library Sci & -19.549 & 8842.421 & .000 & 1 & .998 & .000 \\
\hline TOP17 Math & -19.253 & 21458.198 & .000 & 1 & .999 & .000 \\
\hline TOP21 Public and Protective Services & .025 & .191 & .018 & 1 & .894 & 1.026 \\
\hline TOP30 Commercial Services & -.781 & .288 & 7.353 & 1 & .007 & .458 \\
\hline Constant & .843 & .085 & 99.300 & 1 & .000 & 2.324 \\
\hline
\end{tabular}

a. Variable(s) entered on step 1: TOP01Agriculture, TOP02Architecture, TOP05BusinessManage, TOP06MediaAndComm, TOP07InformationTech, TOP08Education, TOP09EngandIndusTech, TOP10FineAndApplArts, TOP11ForeignLang, TOP12Health, TOP13FamilyandConsSci, TOP14Law, TOP16LibrarySci, TOP17Math, TOP21PublicandProtServ, TOP30CommercialServices.

\section{APPENDIX B}

\section{STUDENT ETCHNICITY TABLE}

Student Ethnicity

\begin{tabular}{llrrrr}
\hline & Frequency & Percent & Valid \% & Cumulative\% \\
\hline CCValid & African American & 4898 & 7.5 & 7.5 & 7.5 \\
\cline { 2 - 6 } & American Indian/Alaska Native & 351 & .5 & .5 & 8.0 \\
\cline { 2 - 6 } & Asian & 7361 & 11.2 & 11.2 & 19.2 \\
\cline { 2 - 6 } & Filipino/a & 1479 & 2.3 & 2.3 & 21.5 \\
\cline { 2 - 6 } & Hispanic & 19636 & 30.0 & 30.0 & 51.5 \\
\cline { 2 - 6 } & Other & 9974 & 15.2 & 15.2 & 66.7 \\
\cline { 2 - 6 } & Pacific Islander & 358 & .5 & .5 & 67.2 \\
\cline { 2 - 6 } & Two or More Races & 1681 & 2.6 & 2.6 & 69.8 \\
\cline { 2 - 6 } & White & 19797 & 30.2 & 100.2 & \\
\hline
\end{tabular}

